\title{
Microstructural modelling in friction stir welding of 2000 series aluminium alloys
}

\author{
Hugh R. Shercliff ${ }^{1, a}$, Michael J. Russell ${ }^{1,2}$, Adam Taylor ${ }^{1}$ and Terry L. Dickerson ${ }^{1}$ \\ 1 Department of Engineering, University of Cambridge, Trumpington St, Cambridge, CB2 1PZ, UK \\ 2 TWI, Granta Park, Cambridge, CB1 6AL, UK
}

Received 2 July 2004, Accepted 5 November 2004

\begin{abstract}
Simple process models are applied to predict microstructural changes due to the thermal cycle imposed in friction stir welding. A softening model developed for heat-treatable aluminium alloys of the 6000 series is applied to the aerospace alloy 2014 in the peak-aged (T6) condition. It is found that the model is not readily applicable to alloy 2024 in the naturally aged (T3) temper, but the softening behaviour can still be described semi-empirically. Both analytical and numerical (finite element) thermal models are used to predict the thermal histories in trial welds. These are coupled to the microstructural model to investigate: (a) the hardness profile across the welded plate; (b) alloy softening ahead of the approaching welding tool. By incorporating the softening model applied to 6082-T6 alloy, the hardness profile of friction stir welds in dissimilar alloys is also predicted.
\end{abstract}

Key words: Friction stir welding (FSW) / modelling / aluminium alloys

\section{Introduction}

Friction stir welding (FSW) of aluminium alloys has moved within one decade from invention to large-scale commercial application in the maritime sector, with research and development continuing in aerospace, rail and automotive transport. A schematic diagram of the process is shown in Figure 1a. The rotating tool has a profiled pin that is traversed along the joint line to make the weld, and a broader shoulder which generates heat by friction (to soften the material) and contains the deformation. Figure $1 \mathrm{~b}$ shows the three characteristic zones in a typical weld: (i) an intense deformation zone called the "nugget"; (ii) a thermo-mechanically-affected zone (TMAZ), where the initial grain structure survives but is deformed; (iii) a heat-affected zone (HAZ).

Process modelling of FSW has been reviewed by Shercliff and Colegrove [1]. Figure 2 summarises the coupled phenomena involved: (i) heat generation and resulting thermal field; (ii) high strain-rate metal flow round the profiled tooling; (iii) the consequent microstructural evolution; and (iv) residual stress, distortion and joint properties. In heat-treatable aluminium alloys, the dominant microstructural effects are changes in the precipitation state of the alloy, which provides the principal strengthening mechanism. Myhr et al. [2-4] developed a

\footnotetext{
${ }^{a}$ Corresponding author: hrs@eng. cam.ac.uk
}

simple model to describe the softening which occurs in the heat-affected zone of arc welded 6082 alloy, and the partial strength recovery which may occur subsequently. The physical basis of the model is the dissolution of the hardening precipitates which provide most of the strength in heat-treatable alloys. The model contains a single internal state variable, the volume fraction of hardening precipitates, and is calibrated to isothermal data, using hardness or resistivity to monitor precipitation state, rather than direct microscopic observation. This makes the model easy to develop and apply in an industrial context. The isothermal model is constructed in such a way that it may be simply integrated over a thermal cycle.

Frigaard et al. [5] and Russell [6] have applied this model to friction stir welding of 6082, using numerical and analytical models to predict the thermal histories. Precipitation in alloys such as 6082 is relatively straightforward, being dominated by the single hardening phase $\mathrm{Mg}_{2} \mathrm{Si}$. For industrial aerospace application, it is of interest to establish whether Myhr et al.'s approach can describe the softening behaviour of more complex $\mathrm{Cu}$-containing alloys, such as 2000 and 7000 series alloys, particularly in the context of welding. Hyoe et al. [7] have demonstrated that the approach is moderately successful for friction stir welding of 7075 alloy, in a peak aged condition. In this paper, consideration is given to alloys 2014 and 2024, in the peak aged and naturally aged conditions respectively. 
(a)

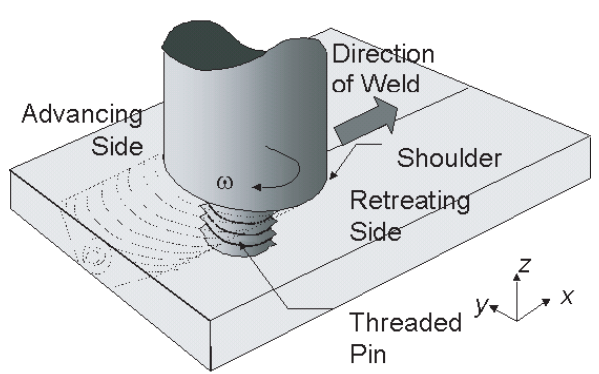

(b)

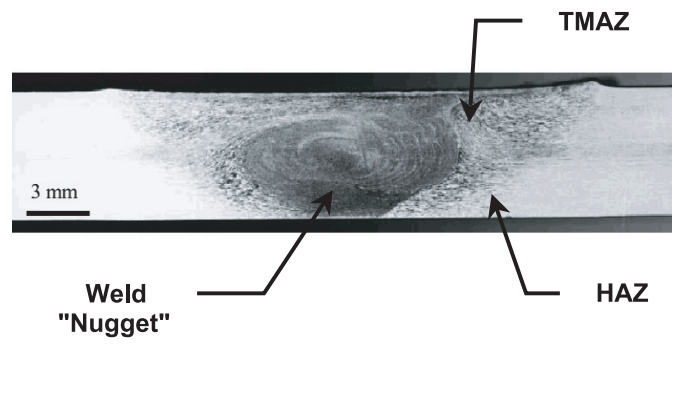

Fig. 1. (a) Schematic diagram of friction stir welding process; (b) Micrograph of a typical weld, showing three characteristic zones (after Leonard [8]).

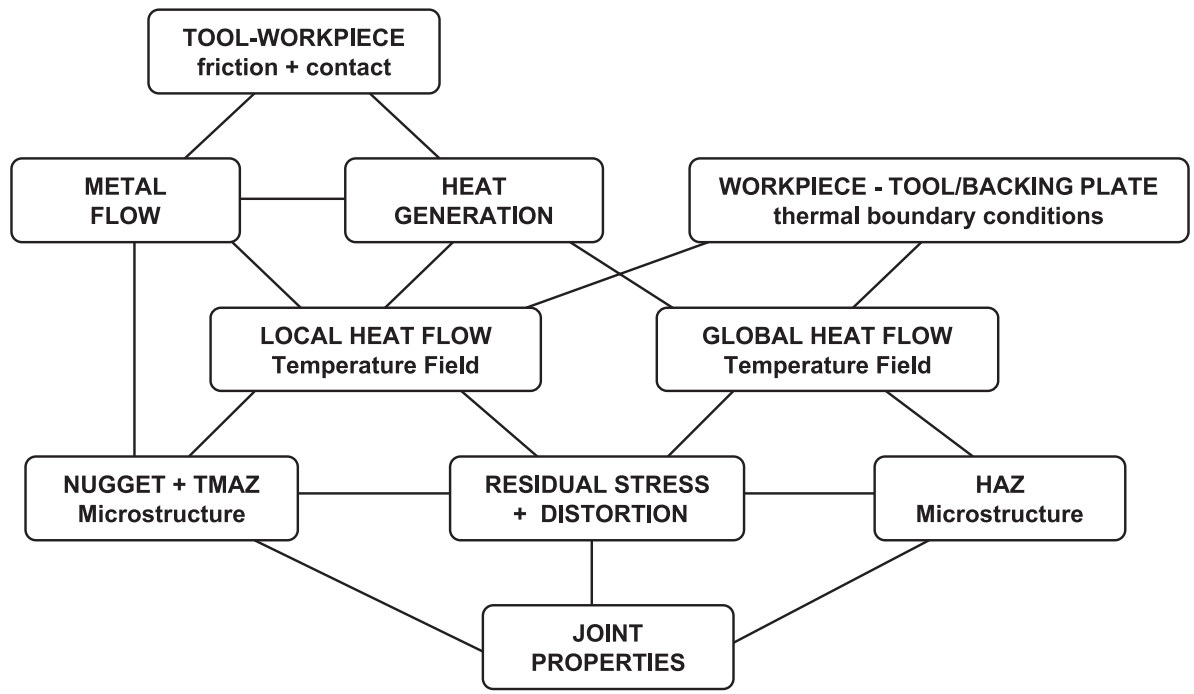

Fig. 2. Overview of process modelling for FSW (after Shercliff and Colegrove [1]).

\section{Experimental work}

The alloy details were as follows: (a) $6.35 \mathrm{~mm}$ thick 2014-T6 aluminium alloy, welded as $152 \times 229 \mathrm{~mm}$ plates at TWI, Cambridge, UK; (b) $3 \mathrm{~mm}$ thick 2024-T3 and 6082 -T6 alloys, welded as $150 \times 60 \mathrm{~mm}$ plates at DLR, Cologne, Germany. The nominal alloy compositions are given in Table 1, and the welding conditions are summarised in Table 2. Temperatures were logged by thermocouples located near the top surface of one plate and at various distances from the weld centre-line. After 3 months of post-weld natural ageing, the hardness profile was measured at mid-thickness, using a Vickers machine under 0.5 or $1 \mathrm{~kg}$ load. Tensile tests were conducted transverse to the welds that included 2024-T3, in the same naturally aged condition. These all failed in the heat-affected zone. The 2024-2024 weld failed at approximately $90 \%$ of the base material strength, while both dissimilar welds failed in the 6082 at approximately $65 \%$ of its initial strength.

Isothermal salt bath experiments were used to characterise the effect of idealised thermal cycles on the microstructure and hardness of the alloys. Small test specimens were machined from unwelded material and
Table 1. Nominal compositions of the alloys (wt \%).

\begin{tabular}{ccccccccc}
\hline Alloy & $\mathrm{Mg}$ & $\mathrm{Cu}$ & $\mathrm{Si}$ & $\mathrm{Zn}$ & $\mathrm{Fe}$ & $\mathrm{Mn}$ & $\mathrm{Cr}$ & $\mathrm{Zr} / \mathrm{Ti}$ \\
\hline 2014-T6 & 0.5 & 4.5 & 0.8 & 0.25 & 0.5 & 0.8 & 0.1 & 0.35 \\
2024-T3 & 1.5 & 4.4 & 0.5 & 0.25 & 0.5 & 0.6 & 0.1 & 0.35 \\
6082-T6 & 0.9 & 0.1 & 1.0 & 0.2 & 0.5 & 0.7 & 0.25 & 0.1 \\
\hline
\end{tabular}

subjected to isothermal treatment at temperatures from 200 to $500{ }^{\circ} \mathrm{C}$. After hold times between 3 and 30000 seconds the samples were immediately quenched and the hardness measured. Hardness measurements were repeated later to assess the strength recovery by natural ageing, after one week for all alloys, and again after 3 months for alloys 2024 and 6082 .

\section{Thermal modelling}

A range of analytical and numerical (finite element) thermal models have been developed for FSW, as well as coupled thermal-flow models using computational fluid dynamics (Shercliff and Colegrove [1]). FSW generates a distributed, primarily surface, heat input. Russell [6] developed a first order analytical model, in which the 
Table 2. Welding conditions.

\begin{tabular}{ccccc}
\hline $\begin{array}{c}\text { Alloy on } \\
\text { advancing side }\end{array}$ & $\begin{array}{c}\text { Alloy on } \\
\text { retreating side }\end{array}$ & $\begin{array}{c}\text { Traverse speed } \\
\left(\mathrm{mm}_{\mathrm{min}}^{-1}\right)\end{array}$ & $\begin{array}{c}\text { Rotation speed } \\
(\mathrm{rpm})\end{array}$ & $\begin{array}{c}\text { Nominal } \\
\text { power }(\mathrm{kW})\end{array}$ \\
\hline 2014 -T6 & $2014-\mathrm{T} 6$ & 80 & 500 & 1.11 \\
2024 -T3 & $2024-\mathrm{T} 3$ & 120 & 400 & 1.28 \\
2024 -T3 & $6082-\mathrm{T} 6$ & 200 & 600 & 1.48 \\
6082 -T6 & 2024 -T3 & 200 & 600 & 1.68 \\
\hline
\end{tabular}

frictional heat generation was aggregated into a point source, as in the classical arc welding solutions due to Rosenthal [9]. To allow for the high conductivity of aluminium, and intermediate plate thickness, superposition of multiple point sources was used, following the method of Myhr and Grong [10]. The heat input was estimated by assuming sticking friction conditions under the shoulder, with the shear yield stress treated as an adjustable parameter to match the peak temperatures measured. Reasonable estimates were also made for heat losses to the tooling and backing plate. This approach was found to give satisfactory predictions of the thermal field for positions beyond the periphery of the tool shoulder, and is applied here to the weld in alloy 2014-T6.

Finite element models are more complex, but enable greater accuracy in predicting the thermal histories in specific welds. Shi et al. [11,12] have presented a finite element analysis for friction stir welding of 2024-T3. The heat input was calculated directly from the torque and rotation speed of the welding machine, and realistic adjustments incorporated to allow for heat losses to the tool shoulder and the steel backing plate. An axisymmetric distributed heat source was used, with a radially increasing heat flux under the shoulder, and a small proportion of the heat associated with the tool pin. No account was taken of the metal flow, which is known to be very localised to the tool surface. The purpose of this model was to provide the thermal history to input into a mechanical analysis of the residual stress. Here the model is used to provide thermal histories for 2024-T3, welded both to itself and to 6082-T6. In the dissimilar alloy welds, the two halves of the plate had the appropriate thermal properties, but it was assumed that the heat inputs and heat losses remained axisymmetric. In practice the thermal properties were sufficiently similar that the predicted thermal field was effectively symmetric.

Figure 3 shows predicted temperature histories using the analytical model for a weld in 2014-T6 alloy. The finite element predicted thermal histories in Figure 4 are for a dissimilar weld between 6082-T6 and 2024-T3. Both cases are compared to thermocouple data. The analytical model (Fig. 3) works well for distances outside the tool shoulder. The loss of accuracy under the tool is of little consequence in the context of predicting hardness profile, since in this region full dissolution is expected, and the detail of the thermal history is not important. The finite element analysis (Fig. 4) captures the peaks of the thermal cycles accurately, including the locations which were "welded over", with the thermocouple close to or passing through the deformation zone. In all cases

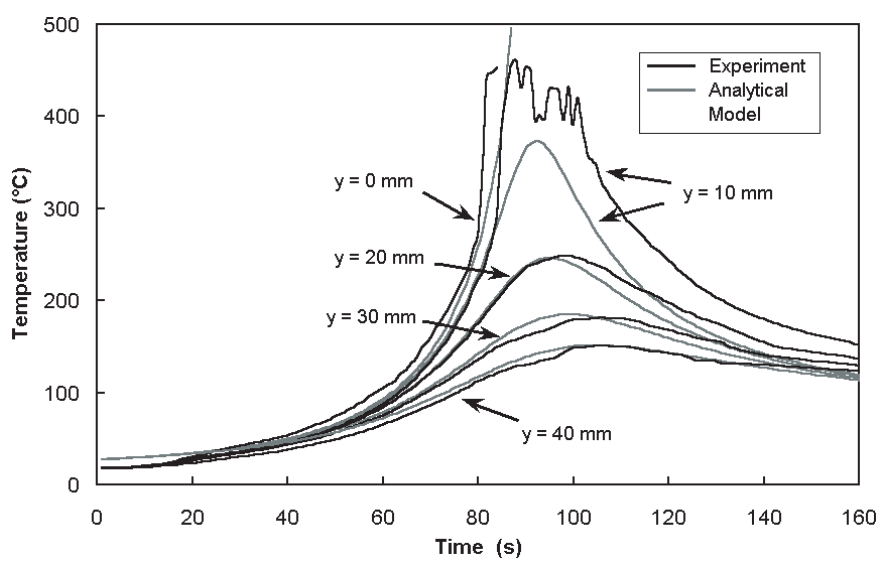

Fig. 3. Measured (black) and predicted (grey) thermal cycles in a 2014-T6 Al alloy friction stir weld, using an analytical heat flow model.

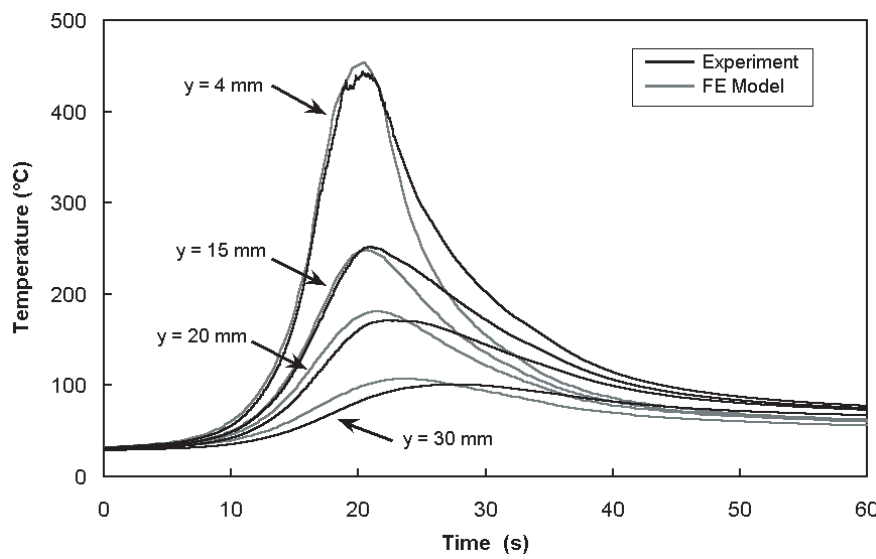

Fig. 4. Measured (black) and predicted (grey) thermal cycles in a 2024-T3 Al alloy friction stir weld, using a finite element heat flow model.

the model predicts faster cooling after welding than was observed experimentally, which reflects uncertainty in the heat transfer conditions between the workpiece and backing plate.

\section{Microstructural softening model and its application to thermal cycles}

\subsection{Softening data for alloy 2014-T6}

The hardness results from the isothermal saltbath tests on 2014-T6 are shown in Figure 5. To clarify the 
extent of natural ageing following a hold at temperature, the difference between the data in Figures 5b and 5a was evaluated (Fig. 5c). Figure 5a shows that softening occurs at all temperatures, the rate increasing with temperature. Both dissolution and over-ageing lead to softening. The extent of subsequent natural ageing for one week (Figs. 5b, c) provides a simple indication of the amount of dissolution, since precipitation of GP zones from any available solute is the only possible hardening mechanism at room temperature. The recovery in strength depends directly on the temperature, with a steady rise in available solute from around $350{ }^{\circ} \mathrm{C}$ to full dissolution at $500{ }^{\circ} \mathrm{C}$. Note that, except at very short hold times, the extent of strength recovery is essentially independent of the prior saltbath hold time. Below $350{ }^{\circ} \mathrm{C}$, natural ageing is negligible, implying that there is little or no dissolution, and that softening is purely due to over-ageing. However, it is assumed that the governing kinetics are the same, since coarsening also occurs by dissolution of the finer precipitates, so this is still the rate-limiting mechanism.

Finally, for alloy 2014-T6, natural ageing experiments were not conducted on the longer timescale of 3 months, as with the other alloys. Alloy 6082 showed dissolution only above $400{ }^{\circ} \mathrm{C}$, but any natural ageing was complete within one week with no further change after 3 months. The 2000 and 7000 series alloys generally show much stronger natural ageing, which can continue for timescales much greater than one week. It is expected therefore that the natural ageing response in 2014 would appear stronger after prolonged timescales, but that the one week data nonetheless provide a reliable indication of the available solute after the isothermal hold.

\subsection{Dissolution model for alloys 2014-T6 and 6082-T6}

Myhr et al. [2-4] modelled the rate of dissolution of hardening particles, $\mathrm{d} f / \mathrm{d} t$, for a given initial volume fraction in 6000 series alloys. The analysis was simplified by scaling the dissolution time to a reference temperature $T_{\mathrm{r}}$ $\left(=300{ }^{\circ} \mathrm{C}\right.$ for both alloys $)$ at which the time for full dissolution was $t_{\mathrm{r} 1}$. The time for full dissolution at another temperature $T$, denoted by $t_{1}^{*}$, is then:

$$
t_{1}^{*}=t_{\mathrm{r} 1} \exp \left[\left(Q_{\mathrm{eff}} / R\right)\left(1 / T-1 / T_{\mathrm{r}}\right)\right]
$$

where $R$ is the universal gas constant, and $Q_{\text {eff }}$ is an effective activation energy for precipitate dissolution in the particular alloy. For 1D dissolution (i.e. assuming platelike precipitates), the particle fraction (normalised by the initial value) depends on time at constant temperature as:

$$
f / f_{0}=1-\left(t / t_{1}^{*}\right)^{1 / 2}
$$

Assuming that the effect of solid solution hardening is small compared to precipitate hardening at all stages of heat treatment, the volume fraction of hardening precipitates may be inferred from hardness data as:

$$
f / f_{0}=\left(H V-H V_{\min }\right) /\left(H V_{\max }-H V_{\min }\right)
$$
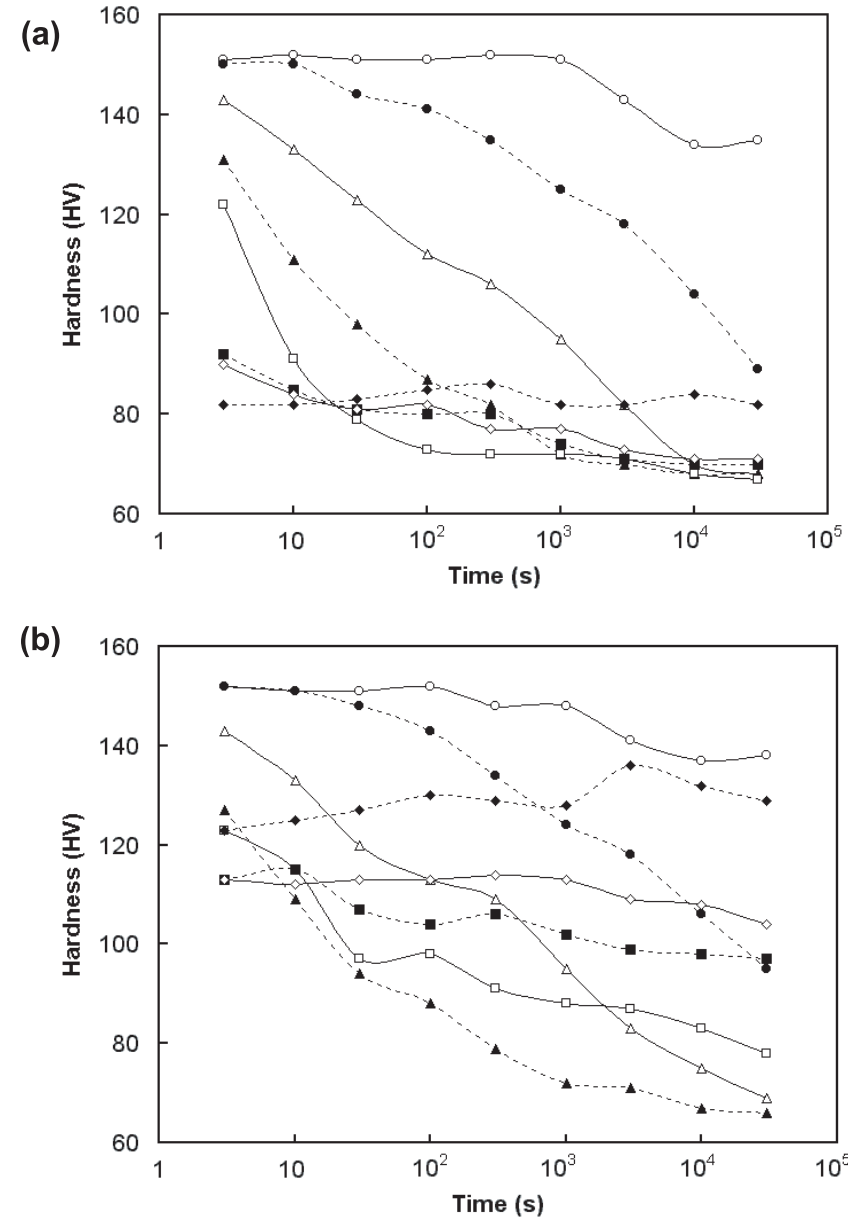

(c)

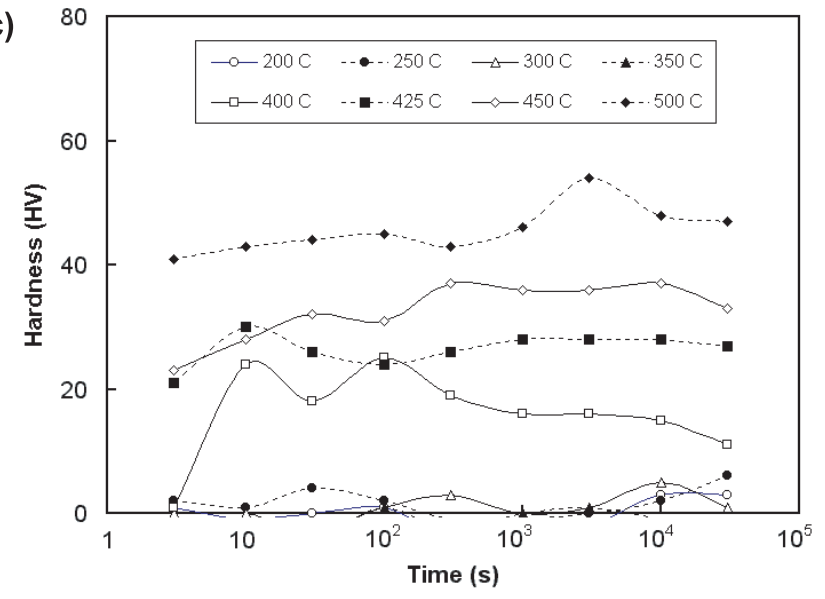

Fig. 5. Hardness data from isothermal hold saltbath tests applied to 2014-T6: (a) as-quenched; (b) after 1 week natural ageing; (c) the change in hardness in 1 week ( $b$ minus $a$ ).

where $H V$ is the measured hardness, and $H V_{\max }$ and $H V_{\min }$ are the maximum and minimum hardness corresponding to peak precipitation and full dissolution respectively.

Following the procedure of Myhr et al., the 2014 hardness data were converted to $f / f_{0}$ using Equation (3), with $H V_{\min }=65$ and $H V_{\max }=155$, and plotted as 
(a)

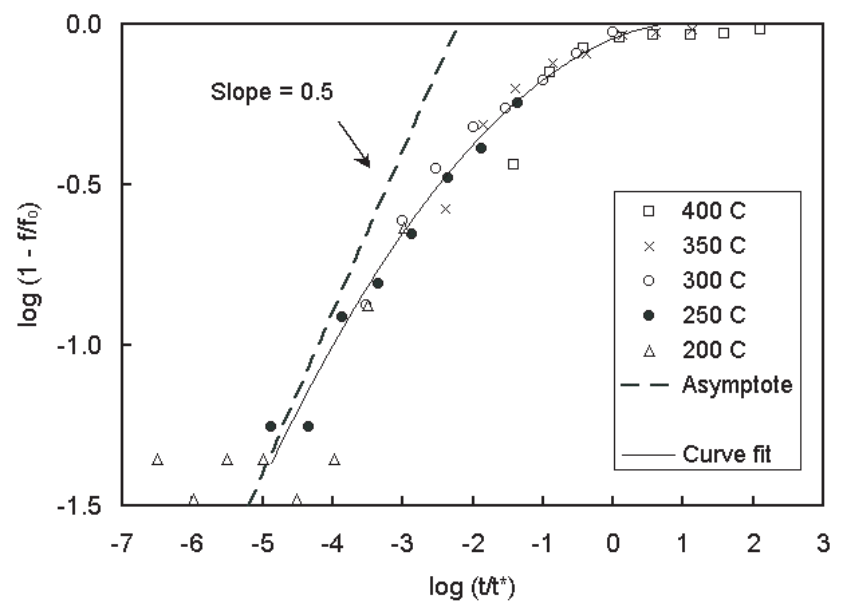

(b)

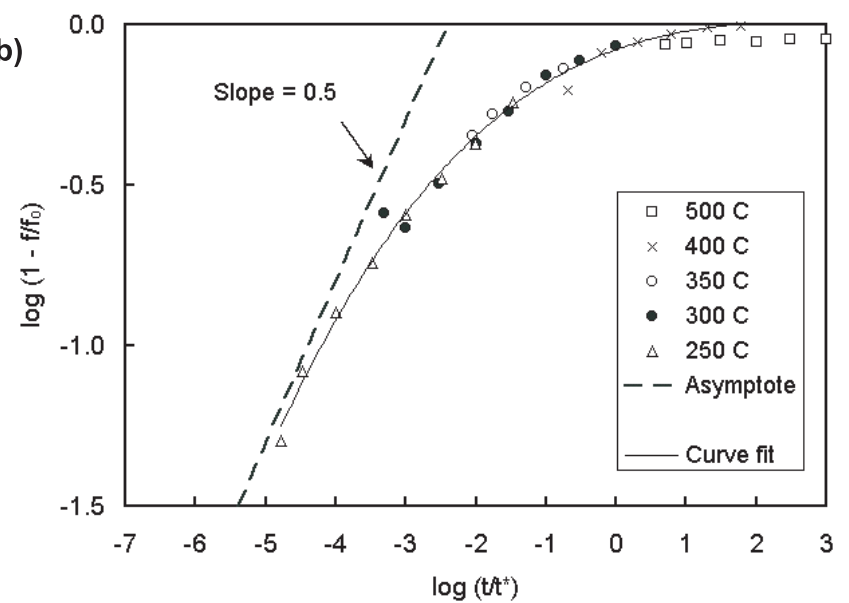

Fig. 6. Application of dissolution model to isothermal softening of: (a) 2014-T6; (b) 6082-T6.

$\log \left(1-f / f_{0}\right)$ vs. $\log \left(t / t_{1}^{*}\right)$. By adjusting $Q_{\text {eff }}$ the data converged to a single dissolution "master curve" (Fig. 6a). The calibrated value of $Q_{\text {eff }}=155 \mathrm{~kJ} \mathrm{~mol}^{-1}$ is very reasonable for an aluminium alloy containing $\mathrm{Mg}$ and $\mathrm{Cu}$. From Equation (2) a straight line of gradient 0.5 is expected. The early stages of dissolution follow this slope, but the slope steadily decreases in the later stages of dissolution, due to impingement of adjacent diffusion fields. Hence a pragmatic semi-empirical approach, which retains the physical basis of the model, is to use the master curve as a "look-up table". This is more accurate than using the calibrated Equation (2), which over-estimates the dissolution rate. Adjustment of the time constant $t_{\mathrm{r} 1}$ simply shifts the master curve along the $(\log t)$-axis, so this parameter is adjusted finally to give full dissolution when $t / t_{1}^{*}=1$. For 2014 -T6, the value was calibrated to a value $t_{\mathrm{r} 1}=10000 \mathrm{~s}$.

Following exactly the same procedure, the model was fitted to softening experiments on the 6082-T6 material used for the dissimilar alloy welds. Figure $6 \mathrm{~b}$ shows the calibrated isothermal "master curve", for which $H V_{\min }=$ $38, H V_{\max }=114$ and $Q_{\text {eff }}=170 \mathrm{~kJ} \cdot \mathrm{mol}^{-1}$ gave the optimum fit, with the time constant again $t_{\mathrm{r} 1}=10000 \mathrm{~s}$. As noted above, 6082-T6 only showed dissolution and natural ageing for hold temperatures above $400{ }^{\circ} \mathrm{C}$, so that overageing dominates to higher temperatures than in the 2014 alloy in the same temper. Nonetheless, a dissolution-based model captures the governing kinetics efficiently, as assumed in the original model applied to this alloy by Myhr and Grong [2].

\subsection{Softening data for alloy 2024-T3}

Figure $7 \mathrm{a}$ shows the hardness data for 2024-T3 immediately after quenching. For high temperatures $\left(>350{ }^{\circ} \mathrm{C}\right)$, the behaviour is similar to the $\mathrm{T} 6$ temper, with the hardness falling at a rate which rises with temperature. It is perhaps surprising that the softening takes a similar time at a given temperature, since the hardening precipitates in the T3 temper are less stable than in the T6 temper. For lower temperatures, the behaviour is different, with the hardness rising to a peak after an initial drop, with the peak being higher and later as the temperature falls. This behaviour reflects the transformation of the initial precipitates in the T3 temper to another more hardening phase - essentially the material is artificially aged by holding at temperatures of $250-300{ }^{\circ} \mathrm{C}$. This resembles an industrial two-step ageing treatment.

Hence in the T3 temper, there are three possible ways in which the initial precipitate structure evolves: dissolution, over-ageing or artificial ageing. Furthermore it is not possible to associate each mechanism with a unique temperature range, since the recovery of strength by natural ageing also now depends on the prior holding time. Figure $7 \mathrm{~b}$ shows the hardness change after 3 months natural ageing against the hold temperature, for 5 hold times. Each temperature shows different behaviour, as follows:

- at $500{ }^{\circ} \mathrm{C}$, full strength recovery is observed, for all hold times;

- at $400{ }^{\circ} \mathrm{C}$, partial strength recovery occurs, to a progressively greater extent with increasing hold time;

- at $350{ }^{\circ} \mathrm{C}$ the reverse is true - partial strength recovery, which falls to nothing as hold time increases;

- at $300^{\circ} \mathrm{C}$, a maximum in strength recovery occurs for times of $5-10$ seconds;

- at $250{ }^{\circ} \mathrm{C}$, a maximum in strength recovery occurs for a time of 30 seconds.

It may be inferred that full dissolution occurred at $500{ }^{\circ} \mathrm{C}$, with partial dissolution after longer times at $400{ }^{\circ} \mathrm{C}$ and shorter times at $350{ }^{\circ} \mathrm{C}$. Longer times at both $350{ }^{\circ} \mathrm{C}$ and $300{ }^{\circ} \mathrm{C}$ give no strength recovery, which suggests over-ageing (at these temperatures). The strength recovery evident at $250{ }^{\circ} \mathrm{C}$ and $300{ }^{\circ} \mathrm{C}$ is also consistent with partial dissolution, since the times for maximum strength recovery coincide with the initial minima in hardness observed immediately after quenching (Fig. 7a), i.e. when most dissolution has occurred just before the onset of artificial ageing.

It was also apparent that the strength recovery by natural ageing in 2024 was incomplete after one week, with substantial further ageing by 3 months. The proportion of the final 3 month hardness achieved in one week varied 
(a)

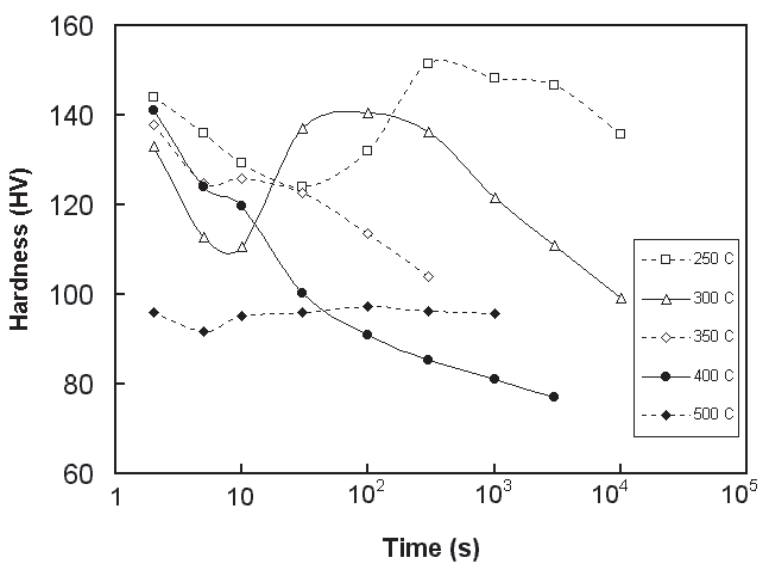

(b)

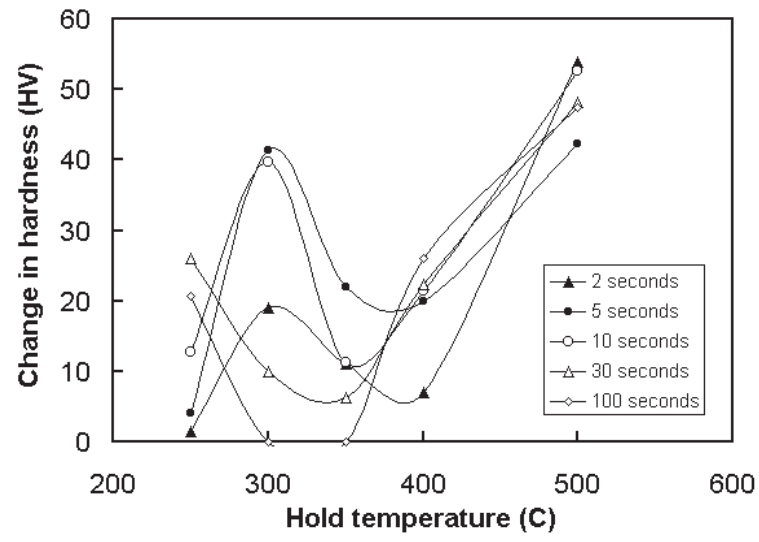

(c)

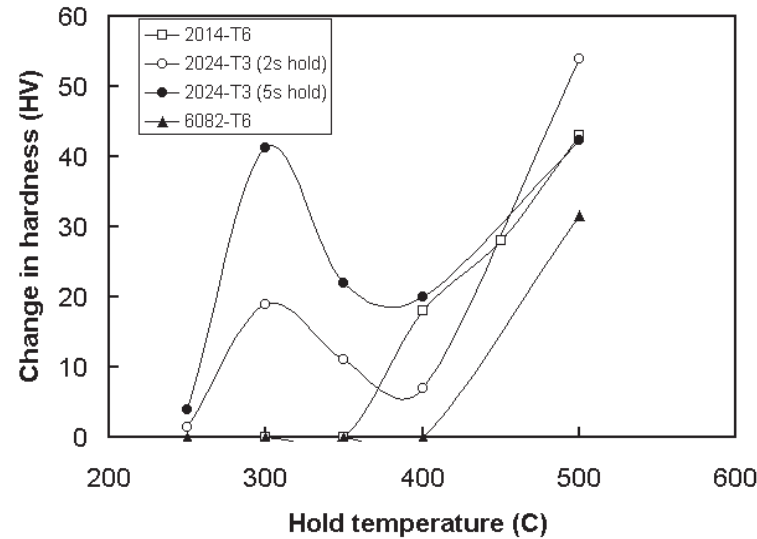

Fig. 7. Hardness data from isothermal hold saltbath tests: (a) 2024-T3, as-quenched; (b) 2024-T3, changes in hardness for different hold times prior to 3 months natural ageing; (c) changes in hardness with natural ageing, for 2014-T6, 6082-T6 and 2024-T3 (2 s and 5 s holds).

significantly, reflecting different incubation times depending on the degree of supersaturation of solute.

The softening behaviour is clearly too complex for a simple model based on a single mechanism to be valid. Even for the temperatures and times which predominantly showed softening by dissolution or over-ageing, there was too little data for a meaningful master curve to be fitted for alloy 2024-T3.

\subsection{Application to thermal cycles}

The isothermal dissolution model may be used to determine $f / f_{0}$ resulting from thermal cycles, as occur in the heat-affected zone of a weld. Two applications of this model are illustrated here: (a) prediction of the extent of softening ahead of the advancing tool; and (b) prediction of the hardness profile across the weld.

For a thermal cycle $T(t)$, the evolution law may be integrated directly over the cycle, such that Equation (2) is replaced by:

$$
\frac{f}{f_{0}}=1-\left[\int \frac{\mathrm{d} t}{t_{1}^{*}}\right]^{1 / 2}
$$

The integral in Equation (4) represents the "kinetic strength" of the thermal cycle with respect to precipitate dissolution. Grong and Shercliff [13] discuss in detail the circumstances in which single internal state variable models for microstructure evolution can be integrated via a kinetic strength. Essentially, the differential evolution law must be isokinetic, and therefore additive (i.e. $\mathrm{d} f / \mathrm{d} t$ is a separable function of $f$ and $T$ ).

For alloys 2014 and 6082, the integral in Equation (4) was evaluated numerically, taking the thermal cycle for given locations in the heat-affected zone as predicted by the analytical or numerical heat flow model. The selected thermal profile was converted into a series of short isothermal steps, of duration $\delta t$. The value of $\delta t / t_{1}^{*}$ was calculated for each isothermal step, and the values summed over the thermal cycle to give the net effective $t / t_{1}^{*}$. This $t / t_{1}^{*}$ value was then converted into a fraction of precipitates dissolved using the master curves in Figure 6, for example, to predict the softening ahead of the welding tool. For predicting the hardness profile, the fraction of precipitates was then converted into an as-welded hardness using Equation (3).

For alloy 2024-T3, a semi-empirical approach was required, since the softening model could not be applied to this alloy. It is apparent from all the saltbath experiments that the peak temperature reached in the thermal cycle is the dominant factor in determining the microstructural change. This suggests that to a first approximation a weld thermal cycle may be replaced by an equivalent isothermal hold at the peak temperature of the cycle, $T_{\mathrm{p}}$. The duration of the equivalent hold time, $t_{\mathrm{eq}}$, should be that which has the same kinetic strength as the true cycle, i.e.

$$
\frac{t_{\mathrm{eq}}}{t_{1}^{*}\left(T_{\mathrm{p}}\right)}=\int \frac{\mathrm{d} t}{t_{1}^{*}(T)}
$$

This requires a knowledge of an appropriate activation energy, to evaluate $t_{1}^{*}$ at each temperature. Even though the softening model could not be fitted to 2024, it is not unreasonable to assume that the underlying diffusion mechanisms will have the same activation energy as in 2014. Hence the thermal cycles for each location in the weld were converted into an equivalent isothermal hold at the peak temperature using Equation (5), with $Q_{\text {eff }}=155 \mathrm{~kJ} \cdot \mathrm{mol}^{-1}$. This gave equivalent hold times of 
the order of 2-4 seconds. The temperature-time combinations were then converted directly into as-welded hardness, by interpolation from the isothermal salt-bath data in Figure 7a.

The measured hardness profiles across the welds include subsequent natural ageing. Hence an estimate is required of the extent of natural ageing, following a given thermal cycle. For 2014-T6 and 6082-T6, the hold temperature primarily determines the extent of natural ageing. Figure $7 \mathrm{c}$ shows the hardening increments determined from the saltbath experiments. Note that the 2014 data are for one week of natural ageing, and may underestimate the value after 3 months. For 6082 the natural ageing time was 3 months (but there is no effect after one week). Figure $7 \mathrm{c}$ also shows the hardening response of 2024, for two times similar to the equivalent isothermal holds for the weld thermal cycles. In this alloy, estimating the hardening increment for a given temperature must also take account of the variation with isothermal hold time. As the extent of natural ageing depends strongly on prior hold time in 2024-T3, there is greater uncertainty in the predictions.

\section{Application of the models to friction stir welds}

\subsection{Prediction of softening ahead of the welding tool}

As a first illustration, the softening model is applied to the thermal history in the material ahead of the approaching tool, for alloy 2014-T6. In heat-treatable alloys, a possible limit on process speed (or tool lifetime) is the need to dissolve the hardening precipitates before the metal enters the high strain-rate deformation zone around the profiled pin. The predicted heating history on the weld centre-line (from the analytical heat flow model) was input to the dissolution model, and the residual fraction of precipitates plotted as a function of distance ahead of the pin (Fig. 8). It can be seen that full dissolution occurs well ahead of the leading edge of the pin. By repeated computation with increasing welding speed, it was predicted that an increase of 2.5 times the welding speed could be achieved before the pin would encounter incompletely dissolved precipitates. A subsequent trial at this speed was successful. This illustrates how simple analytical models can be used to guide process optimisation.

\subsection{Prediction of hardness profiles}

Thermal cycles were evaluated at mid-thickness for all of the welds, at intervals of $1-2 \mathrm{~mm}$. These were combined with the microstructural models to predict the aswelded and naturally aged hardness profiles, for 2014-T6 and 6082-T6. For 2024-T3, the semi-empirical approach detailed above was applied instead.
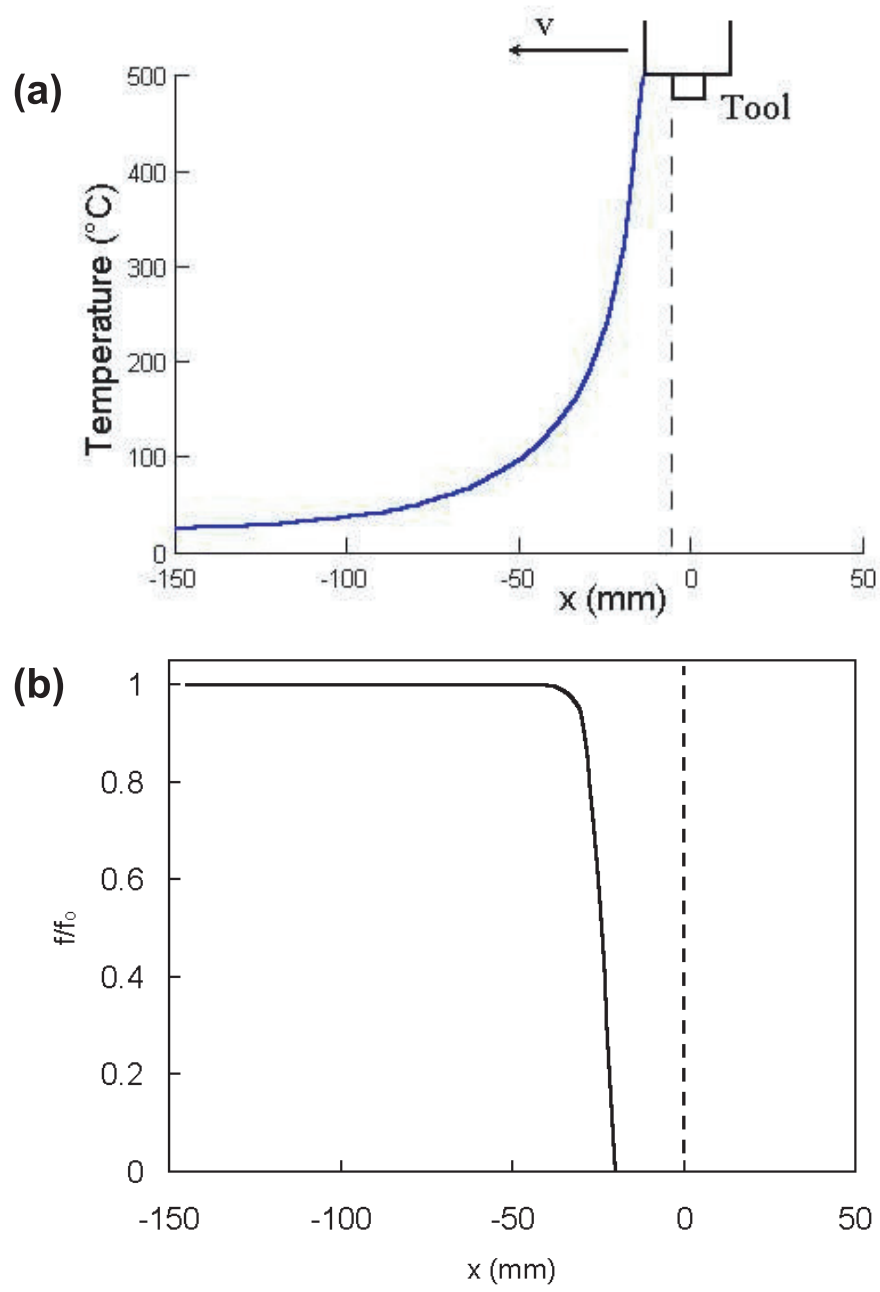

Fig. 8. Prediction of material softening ahead of the tool for a friction stir weld in 2014-T6: (a) temperature profile; (b) fraction of hardening precipitates.

\section{Like-to-like alloy welds}

Figure 9a shows the hardness predicted for alloy 2014-T6, compared with the measured hardness profile at mid-thickness. The figure shows that the model captures the main features of the hardness profile, particularly the minimum strength in the TMAZ/HAZ region, and the maximum recovered strength in the weld nugget (assuming work hardening is not significant). The model predicts that the minimum occurs at the position where natural ageing first occurs - from this point to the weld centre the strength rises to a plateau value across the nugget, where full dissolution and maximum re-ageing occur. Outside the position of minimum hardness, the model over-predicts the loss in hardness, but the overall form of the hardness profile is correct. Since this discrepancy is for the region where natural ageing is negligible, it would make little difference to use a hardening increment for 3 months natural ageing instead of 1 week. Greater accuracy might be achieved using a numerical model for the thermal profiles, but the discrepancy indicates that the microstructural model can capture the main trend rather 


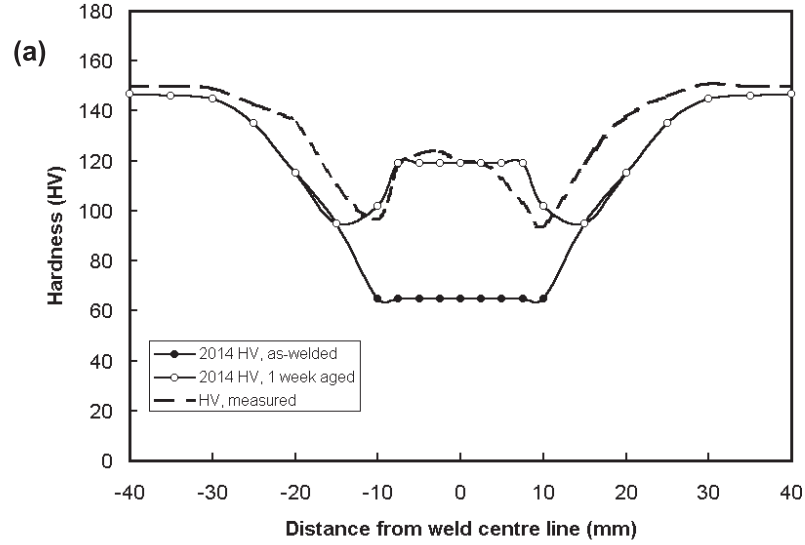

(b)

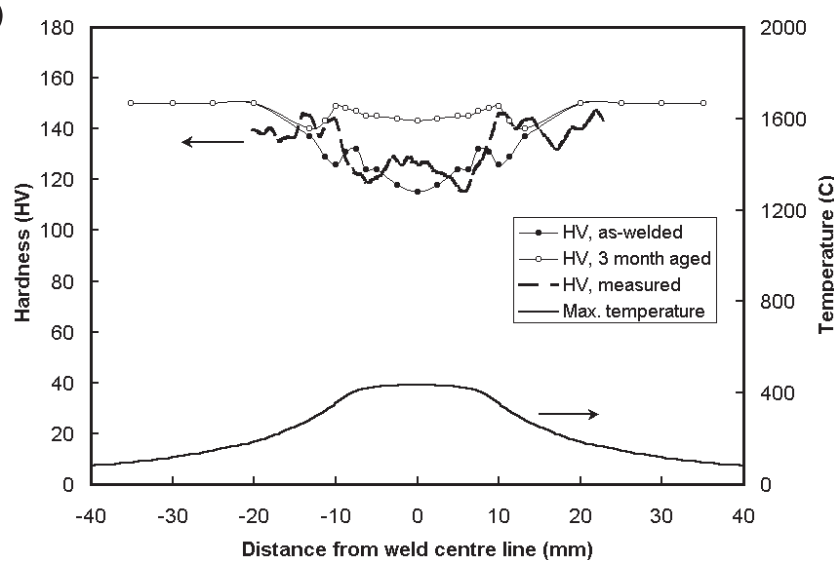

Fig. 9. Predicted and measured hardness profiles across friction stir welds: (a) 2014-T6; (b) 2024-T3.

than the fine detail of the softening in the heat-affected zone.

Figure $9 \mathrm{~b}$ shows the experimental and predicted hardness profiles for the 2024-T3 friction stir weld. The experimental profile is not very smooth, and the model overpredicts the hardness after natural ageing. However, some of the characteristics of the hardness profile are reproduced - the hardness peaks at positions 10-12 mm either side of the centre-line, with a further shallow minimum at $20 \mathrm{~mm}$. The nugget hardness is below the model prediction, which may reflect a detrimental interaction between the deformation microstructure and the subsequent precipitation response. This was not apparent in the 2014 weld however. The minimum measured hardness occurs in the TMAZ adjacent to the weld nugget, and is consistent with the location of tensile failure and a $10 \%$ drop in failure strength.

\section{Dissimilar alloy welds}

Figure 10 shows micrographs of the two dissimilar alloy welds. In these welds, the rotation and traverse directions were the same, but the alloys have been reversed with respect to the advancing and retreating sides of the tool. It is apparent that the degree of mixing is influenced by the handedness of the weld. In both cases, the two alloys can be distinguished in coarse bands in the weld nugget. The torques measured, and hence weld powers, were also sensitive to plate handedness - the alloy on the retreating side is swept across the joint line by the trailing edge of the shoulder, so the alloy on that side of the joint line forms the primary contact with the shoulder. The second weld had a significantly greater heat input, at the same rotation and traverse speed (Tab. 2).

As the thermal properties of the 2024 and 6082 alloys are very similar, and the heat input is assumed to be axisymmetric, the predicted thermal histories are effectively identical on either side of the welds. The hardness profile was predicted for each alloy, and in each case the prediction was extended a short distance across the centre-line, for each of the two initial alloys. The mixed zone is then expected to have a hardness which lies somewhere between these two limits.

Figure 11 shows the predicted and measured hardness profiles for the two dissimilar alloy welds between 6082-T6 and 2024-T3. In both cases the softening model accounts for the hardness profile on the 6082 side very accurately. The discrepancy in hardness on the 2024 side is similar to that in the 2024-2024 weld above, with the hardness being over-predicted, and the measured profile showing some scatter. The hardness of the mixed zone changes abruptly between low and high values, which confirms that the alloys are only mixed macroscopically, as seen in Figure 10. The hardness in the mixed zone lies between the extremes predicted for the two separate alloys, as expected. The minimum hardness occurs in the HAZ of the 6082 , which is again consistent with the location of tensile failure and a $35 \%$ drop in strength.

\section{Discussion}

The single internal state variable model for softening was found to work well for 6082-T6, and captures the hardness profile in friction stir welds in this alloy accurately. The model is physically based on the kinetics of precipitate dissolution, and captures the behaviour of 6082 even though softening is primarily due to overageing. It appears therefore that the underlying dissolution mechanism is rate-limiting in the over-ageing process.

Application of the same approach to 2014-T6 was partially successful, including the stronger recovery of strength by natural ageing in this alloy than in 6082 . The two dominant concerns in engineering terms are thus well-described, that is, the overall width of the softened zone and the minimum hardness (which determines tensile strength). The model was also successfully applied to an investigation of the softening rate ahead of the approaching tool, which may be a factor in determining the maximum process speed in a given alloy.

Alloy 2024 in the T3 temper showed more complex softening behaviour, with three competing mechanisms: dissolution, over-ageing and artificial ageing. The governing mechanism depended on both temperature and hold time, and it was not possible to apply such a simplified model to this alloy. The subsequent natural ageing response also showed a corresponding complex dependence 
(a)

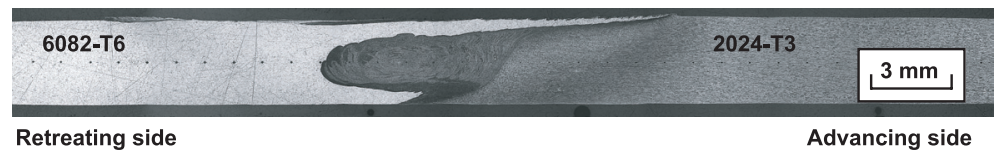

(b)

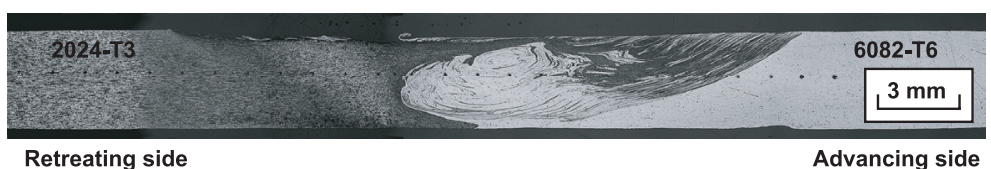

Fig. 10. Micrographs of dissimilar alloy friction stir welds between 2024-T3 and 6082-T6, with advancing side alloy (a) 2024-T3; (b) 6082-T6.

(a)

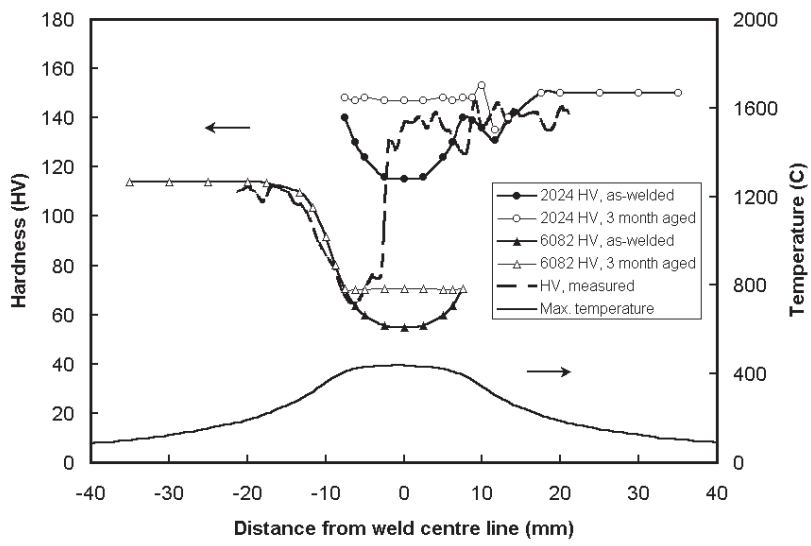

(b)

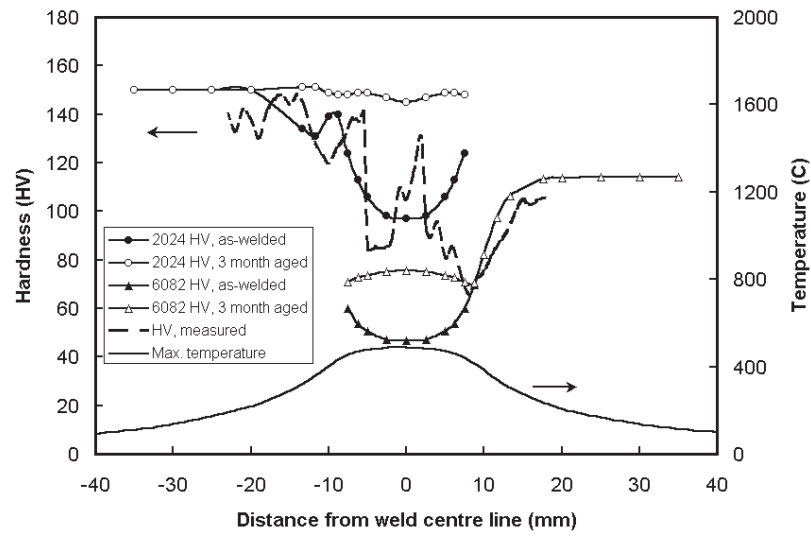

Fig. 11. Predicted and measured hardness profiles across dissimilar alloy friction stir welds between 2024-T3 and 6082-T6, with advancing side alloy: (a) 2024-T3; (b) 6082-T6.

on hold temperature and time. Dissolution and overageing in the isothermal hold could nonetheless be distinguished from one another, as both gave low hardness asquenched, but only dissolution led to subsequent hardness recovery. A semi-empirical approach was used to convert weld thermal cycles into equivalent isothermal holds, such that the as-welded hardness could be interpolated from the isothermal data. Subsequent natural ageing was also estimated, though with greater uncertainty as the hardening increment was sensitive both to isothermal hold time and duration of natural ageing. This approach gave reasonable predictions of the hardness profile in a 2024 friction stir weld. Application of the 2024 and 6082 models simultaneously also provided physically realistic bounds to the hardness in dissimilar alloy friction stir welds.

Single state variable precipitation models therefore have their limits. They are successful for essentially ternary alloys such as 6082 , but begin to break down in more complex $\mathrm{Cu}$-containing aerospace alloys such as 2014 and 2024, particularly in the naturally aged condition. Similar conclusions have been drawn for 7000 series aerospace alloys, from application of the model to softening in friction stir welds in 7010-T6 (Russell [6]) and 7075-T7351 (Hyoe et al. [7]). In each case a master curve could be calibrated using a physically meaningful activation energy. So even though the kinetics of dissolution and over-ageing are complex and alloy-dependent, it appears that a reasonable first-order model can be built on the assumption that the dissolution kinetics are rate-limiting, in a diverse range of heat-treatable alloys. In these alloys the models also gave a reasonable prediction of the overall hardness profile in friction stir welds, but could not capture the fine detail of the softening and subsequent natural ageing.

More sophisticated approaches to this problem have recently been proposed and applied to 6082 and 7108 alloys (Myhr and Grong [14]; Grong and Myhr [15]; Myhr et al. [16]; Nicolas et al. [17]; Nicolas [18]; Nicolas and Deschamps [19]). In these analyses, the evolution of the full size distribution of precipitates is modelled, since this governs the competition between dissolution and coarsening. Both isothermal and ramp heating of previously aged conditions have been investigated, to capture the full thermal history-dependence of the precipitate evolution. Extensive use is made of small angle X-ray scattering (SAXS) data for calibration and validation of the model, providing detailed insight into the underlying competition between dissolution and coarsening. The models currently only apply to ternary extrusion alloys in the 6000 and 7000 series, and are yet to be developed for $\mathrm{Cu}$-bearing aerospace alloys of the 2000 or 7000 series. Precipitation in these alloys shows considerably greater complexity transformation and competition between multiple phases, sensitivity to heating rate, and a stronger tendency for 
dissolution and natural ageing, which may continue over very long timescales.

In friction stir welding, two other metallurgical effects may also play a role in aerospace alloys. Firstly, these alloys are often quench sensitive, i.e. susceptible to coarse precipitation during cooling. It is not yet established whether the cooling rates in friction stir welding are sufficiently fast to avoid this problem, which leads to a loss of strength. Secondly, it is known that precipitates can interact strongly with dislocations in these alloys, with dislocations acting as preferential sites for coarse nucleation and accelerating diffusion. The high strain deformation in the nugget, and the lower strain (but cooler) deformation in the TMAZ, change the dislocation substructure in the alloy, and this may be detrimental to precipitation during cooling. Even though this is not generally the position of lowest strength, there may be important implications for other properties such as fatigue and stress corrosion. These are open questions which have yet to be addressed experimentally in any detail, and provide a future modelling challenge.

Finally, weld process modelling is very relevant to prediction and control of residual stress and distortion. The unstable microstructure in heat-treatable aluminium alloys means that the hot constitutive response will be affected by the internal state of the microstructure. Preston et al. [20] have investigated the effect of history-dependent flow stress on predicted residual stress in 2024-T3 TIG welds. The same method has been applied to the 2024-T3 friction stir weld in this study (Shi et al. [12]). The effect is relatively modest, as the overall constraint on the hot material around the weld limits the sensitivity to the evolving flow stress. However, the current approach provides a pragmatic approach to capturing the first-order softening behaviour. A single state variable approach is well-suited to integration within a full thermomechanical FE analysis, for example, as a control variable in the constitutive hot deformation response. Greater sophistication in the metallurgical model would not appear necessary for this application, and could not be validated effectively due to experimental and numerical uncertainties when dealing with residual stress.

\section{Conclusions}

Analytical and numerical thermal models were successfully used to predict the temperature histories in FSW of aluminium alloys 2014-T6 and 2024-T3, and 2024-T3 to 6082-T6 dissimilar alloy welds. Isothermal softening experiments were used to capture the softening response of 2014 and 6082 alloys, and to calibrate a simple microstructure model based on dissolution of the hardening precipitates. Combining the thermal and microstructure models gave a reasonable prediction of the characteristic hardness profiles across the weld. A semi-empirical approach was required to describe the behaviour of 2024-T3, when a greater range of metallurgical changes occurred, depending on the temperature-time combination to which the material was subjected. Further refinement of the microstructure model is also required to give a more detailed understanding of the possible interactions between precipitation and other features in the microstructure of a friction stir weld, such as the deformation substructure. The softening model for 2014-T6 was also used to predict the softening ahead of the approaching tool, which indicated that a significantly higher process speed could be achieved before the deformation zone would encounter residual hardening precipitates.

Acknowledgements. The authors wish to express their thanks to TWI (UK) for the provision of experimental facilities. Financial support was provided by TWI and the UK Department of Trade and Industry (Post-graduate Training Partnership), and the EU 5th Framework Project JOIN-DMC (Joining Dissimilar Materials and Composites by Friction Stir Welding, Project No.: GRD1-1999-10551). Valuable discussions with Paul Colegrove and Dr. Phil Threadgill at TWI, and the assistance of Takehiro Hyoe in preparation of some of the figures, are gratefully acknowledged.

\section{References}

[1] H.R. Shercliff, P.A. Colegrove, Modelling of friction stir welding, Mathematical Modelling of Weld Phenomena 6, H. Cerjak, H. Bhadeshia (eds.), Maney Publishing, London, UK, 2002, pp. 927-974

[2] O.R. Myhr, Ø. Grong, Process modelling applied to 6082T6 aluminium weldments, 1, Reaction kinetics, Acta Metall. 39(11) (1991) 2693-2702

[3] O.R. Myhr, Ø. Grong, S. Klokkehaug, H.G. Fjær, A.O. Kluken, Process model for welding of Al-Mg-Si extrusions, Sci. Tech. Weld. Join. 2(6) (1997) 245-253

[4] O.R. Myhr, S. Klokkehaug, H.G. Fjaer, Ø. Grong, A.O. Kluken, Modelling of microstructure evolution and residual stresses in processing and welding of 6082 and 7108 aluminium alloys, Proc. 5th Int. Conf. on Trends in Welding Research, 1998, Georgia, USA

[5] Ø. Frigaard, Ø. Grong, O.T. Midling, A Process Model for Friction Stir Welding of Age Hardening of Aluminium Alloys, Met. and Mater Trans. A 32A (2001), 1189

[6] M.J. Russell, Ph.D. Thesis, University of Cambridge, UK, 2000

[7] T. Hyoe, P.A. Colegrove, H.R. Shercliff, Thermal and microstructure modelling in thick plate aluminium alloy 7075 friction stir welds, Friction Stir Welding and Processing II, K.V. Jata, M. Mahoney, R. Mishra (eds.), TMS, The Minerals, Metals \& Materials Society, USA, 2003

[8] A.J. Leonard, Microstructure and Ageing Behaviour of FSWs in Aluminium Alloys 2014A-T651 and 7075T651, Proc. 2nd Int. Symp. on Friction Stir Welding, Gothenburg, Sweden, June 2000

[9] D. Rosenthal, The theory of moving sources of heat and its application to metal treatments, Trans. ASME 68 (1946) 849-866 
[10] O.R. Myhr, Ø. Grong, Dimensionless maps for heat flow analyses in fusion welding, Acta Metall. Mater. 38(3) (1990) 449-460

[11] Q.-Y. Shi, T. Dickerson, H.R. Shercliff, Thermomechanical analyses of welding aluminium alloy with TIG and friction stir welding, Proc. 6th Int. Conf. on Trends in Welding Research, Pine Mountain, GA, USA, ASM International, 15-19 April 2002

[12] Q.-Y. Shi, T.L. Dickerson, H.R. Shercliff, Thermomechanical FE modelling of friction stir welding of Al2024 inclusing tool loads, Proc. 4th Int. Symp. on Friction Stir Welding, Park City, UT, May 2003

[13] Ø. Grong, H.R. Shercliff, Microstructural modelling in metals processing, Progress in Materials Science 47 (2002) $163-282$

[14] O.R. Myhr, Ø. Grong, Modelling of Non-isothermal Transformations in Alloys containing a particle distribution, Acta Mater. 48 (2000) 1605-1615

[15] Ø. Grong, O.R. Myhr, Additivity and Isokinetic Behaviour in relation to Diffusion Controlled Growth, Acta Mater. 48 (2000) 445-452
[16] O.R. Myhr, Ø. Grong, S.J. Andersen, Modelling of the Age Hardening Behaviour of Al-Mg-Si Alloys, Acta Mater. 49 (2001) 65-75

[17] M. Nicolas, J.C. Werenskiold, A. Deschamps, F. Bley, F. Livet, J.P. Simon, Study of precipitate microstructures in the heat-affected zones of a welded Al-Zn-Mg alloy, Proc. Euromat, Rimini, Italy, 2001

[18] M. Nicolas, Évolution de l'état de précipitation dans un alliage $\mathrm{Al}-\mathrm{Zn}-\mathrm{Mg}$ lors de traitements thermiques anisothermes et dans la zone affectée thermiquement de joints soudés, Ph.D. thesis, INP Grenoble, France, 2002

[19] M. Nicolas, A. Deschamps, Characterisation and modelling of precipitate evolution in an $\mathrm{Al}-\mathrm{Zn}-\mathrm{Mg}$ alloy during non-isothermal heat treatments, Acta Materialia 51(20) (2003) 6077-6094

[20] R.V. Preston, H.R. Shercliff, P.J. Withers, S.D. Smith, Finite element modelling of tungsten inert gas welding of aluminium alloy 2024, Sci. Tech. Weld. Join. 8(1) (2003) $10-18$ 